\title{
WHAT ENABLES RETIRING ADULTS LIVING ON GREAT BARRIER ISLAND TO MANAGE LONG-TERM CHRONIC CONDITIONS?
}

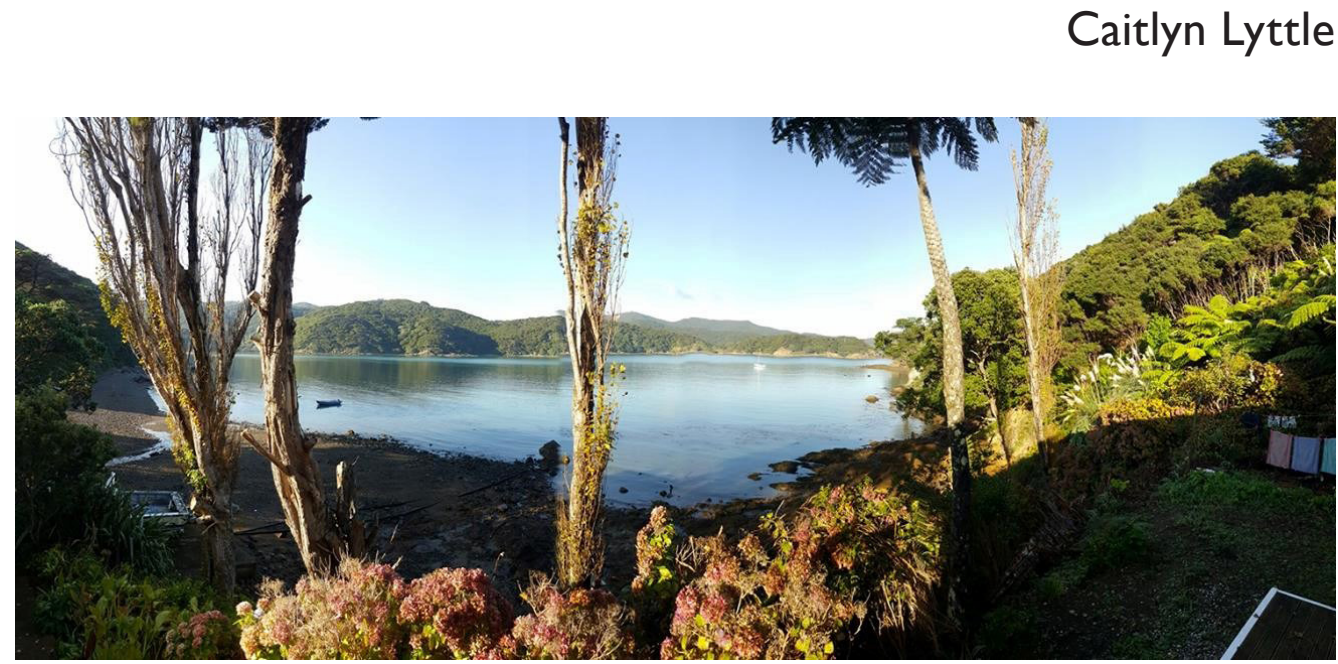

Figure I. 'View from home' - Motairehe, Great Barrier Island. Source: Rhoderick Lyttle.

\section{INTRODUCTION}

Aging is an inevitable part of life. Many individuals choose to spend the last period of their life in an environment that is relaxing and scenically attractive, features notable to Great Barrier Island (King \& Connell, 1999). Great Barrier Island (Aotea 'White Cloud') is situated 100 kilometres in the outer part of Auckland, New Zealand in the Hauraki Gulf. Great Barrier is known for its sandy beaches, native bushes and birds, isolated from the many luxuries that people within the mainland of New Zealand have access to (Ross \& Crawley, 20 I8). It is not surprising that one of the largest groups currently living on Great Barrier are the over 60 year olds, many having lived on the Island intermittently throughout their life (Howie \& Robertson, 2017). This aging population may already have developed a chronic health condition or are more likely to during their period of retirement (Westerlund, et al., 2010 ,). This review of literature discusses the challenges faced by this population group and how they manage their health whilst living on an isolated, rural Island. Identified challenges to rural Island living include isolation, lifestyle maintenance, transportation, limited healthcare, lack of quality health care and financial burden (Goins, Williams, Carter, Spencer, \& Soloveia, 2006). The influence of these challenges will be explored to understand how this 60 plus year old population manage their health, specifically long-term chronic conditions. Great Barrier Island has shown to host a great number of Māori compared to other areas within the country (Statistics New Zealand, 2013). Health providers in this rural setting should recognise the high population of Māori living on the Island and adapt their care to suit the needs of this group. An exploration of this population will be provided, outlining the health disparities faced by Mãori and the duty of health providers in delivering culturally safe care. 
Collaboration, among patients, health providers and within the multidisciplinary team is a key theme that enables the population of retiring adults to manage their health conditions on Great Barrier Island. Two recommendations will be provided to aid this population in their management of chronic conditions.

\section{COLLABORATION}

Geographically separated from urban populations, rural Island living can pose numerous challenges. Great Barrier Island is a rural and isolated part of New Zealand, a large number of the population here are reaching 65 years and above and retiring adult inhabitants (Statistics New Zealand, 2013). To achieve positive health outcomes in this group, the health consumer and professionals need to work together. Facilitating the health needs of retired adults managing long-term chronic conditions requires good communication, resources, and information to be provided by health professionals. A partnership between the health consumer and health professional encourages positive health outcomes to be obtained, improving the wellbeing of the individual receiving care (Reed, 201I). Effective communication within the multidisciplinary team promotes a patient-centred care approach and aims to cover a wide range of patient needs (Barr, Koppel, Reeves, Hammick, \& Freeth, 2005). Positive interdisciplinary collaboration has shown to benefit the patient, organisation, and healthcare provider (Petri, 20 I0). Adopting these values of collaboration can be beneficial to patient health outcomes in both an urban and rural setting which, proves necessary to sustain living on an isolated rural Island. Without collaboration between health providers on Great Barrier Island and Auckland, medical emergencies would be detrimental for the patient. The recommendation to work alongside iwi promotes cultural awareness in health providers and encourages Māori, a high-risk group of developing chronic conditions, to ensure their health needs are met.

\section{DISCUSSION}

According to Goins, Williams, Carter, Spencer and Soloveia (2006), some barriers rural older adults face in their accessibility to health care include transportation difficulties, limited health care supply, lack of quality health care, social isolation and financial constraints. There is a necessity to protect and improve the health outcomes for rural New Zealanders as they face many barriers in their ability to access health care (Fraser, 2006). Living on an Island brings additional maintenance challenges, as there is a necessity to adopt a self-sustaining lifestyle due to limited resources (Choi, 2009). All these factors are likely to influence the retiring populations health status and their ability to manage their chronic conditions. Barriers will now be discussed.

\section{Social isolation}

According to Findholt (2013), often those managing chronic conditions in a rural setting feel both emotionally and physically isolated, expressing a desire to be surrounded by people going through a similar situation. Talking to someone who understands what you are going through can be therapeutic and allows the person to feel like they are not alone. The model of health, Te Whare Tapa Whā, encompasses four aspects of health that if fulfilled, promotes wellbeing (Ministry of Health, 2017). If one of the dimensions is missing or lacking, the individual may become unbalanced and unwell. Family health is an aspect of the model and is the capacity to belong, care and share among a wider social system (Ministry of Health, 2017). Based on this model, the retiring adults on Great Barrier with chronic conditions who feel socially isolated are likely to see a decrease in their health and wellbeing. It is important that there are services available to counter this issue. Whilst this may be the case for some, other rural communities explain that their isolated living positively enhances community support and cohesion (Findholt, 2013). A nurse living on the 'Barrier' (Great Barrier Island) claims there is a strong sense of community, acknowledging that this is from her experiences and may not apply to all individuals living on the Island (Ross \& Crawley, 2018). 


\section{Economics}

Financial burden is often prevalent in isolated rural areas (Fraser, 2006). Freight charges to bring supplies to the Island leads to an increase in the price of consumables, particularly food, petrol/diesel and cooking gas (Great Barrier Island Community Health Trust, 2020). There are no supermarkets, so often locals will eat home-grown or home-killed food (Mann \& Skelton, 2017). On the Island, "950 people live without reticulated power or water" (Mann \& Skelton, 2017, p. I). Instead, power is self-generated; warmth in homes supplied by woodstoves/burners and water obtained by water tanks (Mann \& Skelton, 2017). Expenses to maintain appropriate living conditions on an isolated Island comes with a cost as the increased fuel prices are the only available source to refill the generators which power homes. This financial burden may prove difficult for some individuals, creating stress in a time dedicated to relaxing after years of work. Financial stress can influence physical, mental, and emotional health (Choi, 2009). Poorly managed stress among this population on the island can lead to insufficiently managed chronic conditions, reducing wellbeing in numerous aspects of health. According to Health Point (2019), the enrolled patient fees to access a General Practitioner (GP) at Aotea Health are:

- Under 14 years: free

- 14 to 79 years: $\$ 19$

- $80+$ years: $\$ 13$

According to CityMed Ltd (2020), an Auckland Health practice, the enrolled patient fees to see a GP are as follows:

- Under 12 years: $\$ 20$

- 13 to 17 years: $\$ 40$

- 18 to 64 years: $\$ 69$

- $65+$ years: $\$ 67$

There is a significant difference in the cost to visit a doctor between the rural practice on Aotea to an urban practice in Auckland. The cheaper prices to see a GP on Great Barrier makes it more affordable for Island residents to access health care, enabling them to seek support and manage their chronic conditions. However, Great Barrier only has three GPs at the practice, suggesting it would be difficult to be seen promptly due to the ratio of doctors to patients on the Island. Auckland has a vast number of GP clinics available to the city residents, meaning they are likely to be seen faster than those at Great Barrier. This could have negative outcomes for those living on Great Barrier as their reduced ability to receive prompt care could lead to an increase in the severity of symptoms they are experiencing.

\section{Lifestyle maintenance}

The increased cost of food on the Island encourages many to adopt self-sustaining eating choices of gardening and hunting. The manual labour required to maintain this lifestyle can have a positive impact on the management of chronic conditions. Physical exercise is recommended for reducing the severity of long-term conditions such as diabetes and heart disease (Nicklett \& Kadell, 2013). Eating fruit and vegetables has positive health outcomes in the management of chronic conditions, showing be a protective factor against hypertension, coronary heart disease and atherosclerosis in older adults (Nicklett \& Kadell, 20I3).

For many of these people, the housing is not adequate and requires manual labour to meet suitable living conditions. A lack of electricity calls for an individual responsibility to light fires or power generators to keep warm. Septic tanks and water tanks are also commonly used on the Island (Howie \& Robertson, 2017). Some older adults may find it difficult to maintain these essential living requirements and should take into consideration their physical ability to sustain a living on Great Barrier Island. 


\section{Transport}

The sparsely populated island and the limited number of health care services impacts one's ability to receive health services. Many are required to travel great distances to visit their GP or nurse. Travel around the Island can prove difficult for households without a vehicle as there is no public transport (Great Barrier Island Community Health Trust, 2020). Fuel costs can be quite expensive in comparison to urban populations, which may deter people from having their own personal source of transport. Research has shown links between resource accessibility and health status, indicating that those with inhibited access to be disadvantaged in numerous aspects of health (Fraser, 2006).

Additional transportation issues that prevail on the island include a lack of traffic lights and streetlights, where there is a pure reliance on natural lighting to illuminate the roads (Mann \& Skelton, 2017). Also, transport from the island to the mainland is weather dependent and expensive, with the two options of ferry or flying (Great Barrier Island Community Health Trust, 2020).

\section{AOTEA HEALTH CARE}

The Great Barrier Island Community Trust (2020) is an organisation that purchases necessary medical supplies and communication sources. They work in conjunction with Aotea Health Ltd, a primary health care provider which offer health care services to those on the island. The Aotea Health Ltd team consist of midwives, rural nurses, general practitioners, administrators and community workers (Health Point, 2019). The rural nurses' role encompasses many aspects of health, including mental health, district nursing, public health, Plunket and practice nursing (Health Point, 2019). Services are available to people throughout the lifespan, from antenatal care to palliative care (Health Point, 2019).

A rural nurse who has worked and lived on Great Barrier Island for over 30 years says she had cared for four to five generations of one family/whānau (Ross \& Crawley, 20l8). This enabled her to develop meaningful therapeutic relationships with clients and their families, the remote island means that "you already know them and they already know you" (Ross \& Crawley, 2018, p. 31). Nursing in a rural setting can pose boundary challenges between the nurse and client as there are personal and professional aspects of the relationship. Nurses who have a personal and professional relationship with the client are at risk of being biased in their delivery of care. Therefore, there is a need for nurses to establish relationship boundaries to ensure the care delivered is safe and appropriate (Howie, 2008).

\section{Limited health care}

The Aotea Health Ltd team on Great Barrier aims to cater to the needs of the residents on the Island by offering a full range of primary health services. They also offer nursing emergency services and an after-hours on-call doctor (Health Point, 2019). However, they lack resources for an acute emergency and require assistance from services on the mainland. In the case of a medical emergency, the team at Aotea Health work collectively with Auckland emergency services to retrieve the patient, often by helicopter and take them to an Auckland hospital (Health Point, 2019). Older adults with chronic conditions are a high-risk group to experience a medical emergency which requires hospitalisation (Chang, et al., 2019). Great Barrier Island has only so many resources available for residents undergoing a medical emergency and the delay in care could have detrimental consequences. Working with interdisciplinary teams enables the safety of island residents. Without collaboration between health professionals on Great Barrier and Auckland, the safety of the Island residents is in jeopardy. 


\section{Cultural considerations}

There is a high population of aging Māori on Great Barrier Island. The median age of Māori on the Barrier is 37 years old compared to the median of 23.9 for all Māori in New Zealand (Statistics New Zealand, 2013). The Māori population is overrepresented in statistics of numerous chronic conditions, including cardiovascular diseases and diabetes, conditions that are often preventable through lifestyle changes (Gu, Warren, Kennelly, Neuwelt, \& Harwood, 2014). Māori are shown to be disadvantaged in their health literacy knowledge compared to nonMāori (Lambert, et al., 2014). As a health professional, it is essential to gain an understanding of your patients' health literacy to ensure they are indeed following their recommended care plan. Accommodating to the cultural needs of Māori clients and adhering to the Treaty of Waitangi allows for appropriate and safe care. The second recommendation is aimed to incorporate the cultural needs of Māori living on Great Barrier Island. Providing this group with education on the chronic health risks that they are susceptible to can be used as a prevention and management tool, with hopes of achieving good health and wellbeing.

\section{RECOMMENDATIONS}

\section{A mobile clinic to provide health to islanders, including aging adults living with long-term chronic conditions}

One recommendation is for a mobile health clinic to be present on Great Barrier Island. This would improve patient access to health services and encourage people to act on their health. It would be beneficial if there were mobile clinic runs specifically catered to aging adults with chronic conditions. This could serve to educate patients, prevent the severity of disease, and manage current symptoms. The health professional supplying individuals with coping strategies will provide individualised care and advise on the management of their condition. Having individuals from different aspects of the multidisciplinary team allows different community needs to be met, ensuring the health and wellbeing of clients.

A mobile health clinic in the USA proved to be an effective tool for chronic disease management. According to Yu, Hill, Ricks, Bennet and Oriol (2017), patients who visited the mobile clinic over a two-year period had a significant average reduction of $10.7 \mathrm{mmHg}$ systolic and $6.2 \mathrm{mmHg}$ diastolic blood pressure among their patients with hypertension. Managing hypertension is essential for many chronic conditions, a significant decrease such as this reduces the relative risk of both myocardial infarction and stroke (Yu, Hill, Ricks, Bennet, \& Oriol, 20 I7). Mobile clinics are said to reduce barriers to health services, including "distance, social isolation, lack of time and cultural issues" (Bidwell, 200I, p. 26). Great Barrier has a sparse population, having a mobile clinic would aim to reduce some of these inequalities that exist among rural population access to health.

\section{Educate the local marae on the management of long-term chronic conditions}

A great number of the population on Great Barrier Island are Māori, many are associated with local marae on the island (Statistics New Zealand, 2013). Māori are statistically supported to be shown to have poorer health outcomes than non-Māori due to a high representation in the following areas which influence health: poorer social and economic status, high levels of behavioural risk factors (e.g. smoking, drinking, drug abuse) and poorer access to some health services (Ministry of Health, 200I). These poorer health outcomes make Mãori a high-risk group of developing long-term chronic conditions. Intervention tools on the marae aim to reduce the prevalent health inequity, promoting health and educating individuals on how to prevent and manage chronic conditions. The marae is a space that Māori often gather, practise cultural beliefs and share knowledge among one another (Tapsell, 2002). Educating individuals in a place as such encourages a discussion to be had on ways that Māori of all ages can achieve positive health. 
A health promotion and diabetes prevention programme was conducted on an urban marae (Simmons \& Voyle, 2003). The research concluded that the majority knew little about diabetes, ate high intakes of fatty foods and had low levels of physical activity (Simmons \& Voyle, 2003). This programme was shown to increase the potential for the adoption and maintenance of healthy lifestyle behaviours; the marae had taken action to run their own health programme to educate their people (Simmons \& Voyle, 2003). Trialling a health promotion and chronic disease prevention programme on Great Barrier Island would be beneficial in numerous ways. It could encourage a discussion around Māori health and educates this high-risk group on what actions can be taken to prevent the development of chronic diseases.

\section{CONCLUSION}

Retiring adults who live on Great Barrier Island face challenges that differ from those living on the mainland of New Zealand, the rural environment creating barriers in numerous areas influencing health. Managing a chronic condition with fewer health professionals available can lead to the severity of symptoms and overall poorer health. Additionally, there are transportation issues which inhibit these people to access services. Isolation and financial burden can negatively influence the wellbeing of islanders, influencing other aspects of overall health. The lifestyle upkeep of living 'island style' may impose on the relaxation those often seek during a period of retirement. Health providers are tasked to consider the rural situation of the population living on Great Barrier and deliver care that is accessible and accommodates to their needs. Achieving this requires collaboration between all individuals involved in the care plan of patients. A mobile clinic is a means to try and reduce the health inequalities faced by those living on an isolated rural Island. An increase in access to services would ideally lead to better health outcomes in the population, including those managing chronic conditions. Additionally, if education on disease management was provided on the marae could improve the health of Māori, a high-risk group.

Caitlyn Lyttle is a third-year nursing student at Otago Polytechnic. She has an interest in both Māori and rural health, areas that specify to the population on Great Barrier Island. As a Māori individual whose family marae is located on the island, she was passionate to explore this topic.

Correspondence to Caitlyn Lyttle: Otago Polytechnic, School of Nursing, Dunedin, New Zealand. Email address: caitlynmlyttle@gmail.com

\section{REFERENCES}

Barr, H., Koppel, I., Reeves, S., Hammick, M., \& Freeth, D. (2005). Effective interprofessional education: Argument, assumption and evidence. London: Blackwell Publishing.

Bidwell, S. (200I). Successful models of rural health service delivery and community involvement in rural health: International literature review. Christchurch: Centre for Rural Health.

Chang, E. T., Piegari, R., Wong, E. S., Rosland, A., Fihn, S. D., Vijan, S., \& Yoon, J. (2019). Which patients are persistently high-risk for hospitalization? The American Journal of Managed Care, 25(9), 274-281.

Choi, L. (2009). Financial stress and its physical effects on individuals and communities. Community Development, Investment Review, 120-122.

CityMed Ltd. (2020). Fees. Retrieved from CityMed Medical Centre: http://www.citymed.co.nz/fees/ 
Currie, J., \& MacLeod, B. (2008). First do no harm? Tort reform and birth outcomes. The Quarterly Journal of Economics, I23(2), 795-830.

Findholt, N. E. (2013). The culture of rural communities: An examination of rural nursing concepts at the community level. In C. A. Winters (Ed.). Rural nursing: Concepts, theory, and practice, (pp. 367-376). New York: Springer Publishing Company.

Fraser, J. (2006). Rural health: A literature review for National Health Committee. Wellington: Health Services Research Centre.

Goins, R. T., Williams, K. A., Carter, M. W., Spencer, S. M., \& Soloveia, T. (2006). Perceived barriers to health care access among rural older adults: A qualitative study. The Journal of Rural Health, 2I(3), 206-213.

Great Barrier Island Community Health Trust. (2020). Great Barrier Island Community Health Trust information. Retrieved from Great Barrier Island Community Health Trust: https://greatbarrierislandcommunityhealthtrust.org.nz/

Gu, Y., Warren, J., Kennelly, J., Neuwelt, P., \& Harwood, M. (2014). Cardiovascular disease risk management for Maori in New Zealand general practice. Journal of Primary Health Care, 6(4), 286-294.

Health Point. (2019, November II). Aotea Health. Retrieved from Health Point: https://www.healthpoint.co.nz/gps-accidenturgent-medical-care/gp/aotea-health/

Howie, L. (2008). Contextualised nursing practice. In J. Ross (Ed.). Rural nursing: Aspects of practice (pp. 32-49). Dunedin: Rural Health Opportunities.

Howie, L., \& Robertson, A. (2017). Island nurses: Stories of birth, life and death on remote Great Barrier Island. Auckland: Allen \& Unwin.

King, R., \& Connell, J. (1999). Small worlds, global lives - Islands and migration. London: The Cromwell Press.

Lambert, M., Luke, J., Downey, B., Crengle, S., Kelaher, M., Reid, S., \& Smylie, J. (2014). Health literacy: health professionals' understandings and their perceptions of barriers that Indigenous patients encounter. BMC Health Services Research, 14:614, $1-10$.

Mann, B., \& Skelton, C. (2017, June 4). What it's like to live off the grid, free range, in community on Great Barrier Island. Retrieved from Stuff: https://www.stuff.co.nz/travel/destinations/nz/92569454/what-its-like-to-live-off-the-grid-free-range-in-community-ongreat-barrier-island

Ministry of Health. (200I, May). Priorities for Maori and Pacific Health: Evidence from epidemiology. Retrieved from Ministry of Health: https://www.moh.govt.nz/notebook/nbbooks.nsf/0/A31842D9|480064FCC256A55007A980A/\$filePrioritiesForMaorian dPacificHealth.pdf

Ministry of Health. (2017, May 18). Māori health models - Te Whare Tapa Whā. Retrieved from Ministry of Health: https://www. health.govt.nz/our-work/populations/maori-health/maori-health-models/maori-health-models-te-whare-tapa-wha

Nicklett, E. J., \& Kadell, A. R. (2013). Fruit and vegetable intake among older adults: a scoping review. National Institute of Health, 305-312.

Petri, L. (2010). Concept Analysis of interdisciplinary collaboration. Nursing Forum, 45(2), 73-82.

Reed, A. (20II). Nursing in partnership with patients and carers. Exeter: Learning Matters Ltd.

Ross, J., \& Crawley, J. (2018). Stories of nursing in rural Aotearoa: A landscape of care. Dunedin: Rural Health Opportunities.

Simmons, S., \& Voyle, J. A. (2003). Reaching hard-to-reach, high-risk populations: Health Promotion International, I8(I), 4I-50.

Statistics New Zealand. (2013). 2013 Census QuickStats about a place: Great Barrier Local Board Area. Retrieved from Stats NZ: http://archive.stats.govt.nz/Census/20I3-census/profile-and-summary-reports/quickstats-about-a-place.aspx?request_ value $=|36| 6 \&$ parent_id $=|3| 70 \&$ tabname $=\& s c \_$device $=$pdf

Tapsell, P. (2002). Marae and Tribal Identity in Urban Aotearoa/New Zealand. Pacific Studies, 25(I), I4I- I7I.

Westerlund, H., Vahtera, J., Ferrie, J., Singh-Manoux, A., Pentti, J., \& Melchoir, M. (20I0,). Effect of retirement on major chronic conditions and fatigue: French GAZEL occupational cohort study. The BMJ, I-7.

Yu, S. W., Hill, C., Ricks, M. L., Bennet, J., \& Oriol, N. E. (2017). The scope and impact of mobile health clinics in the United States: A literature review. International Journal for Equity in Health, 16(1), 178. 